\title{
Analysis of Urban Heat Island Phenomenon and Mitigation Strategies for Tirana, Albania
}

\author{
Vilma Picari, Sokol Dervishi \\ Department of Architecture, Epoka University, Tirana, Albania
}

\begin{abstract}
The Urban Heat Island (UHI) is a phenomenon that affects many cities and citizens worldwide. As a developing city, Tirana has had a rapid urbanization with a high population increase and like other Mediterranean cities has faced many thermal issues from high urban temperatures.The present paper aims to analyse the urban heat island phenomenon during summer time in Tirana and to propose urban heat island mitigation techniques based on cool materials and urban greenery. Three sites with different characteristics have been selected for the analysis and mitigation strategies.
\end{abstract}

\section{Introduction}

The urban air temperature is eventually increasing all around the world. The intensity of the UHI depends strongly on urban characteristics, synoptic conditions, local meteorological features, the type of urban materials and the presence (or lack) of green. Furthermore, anthropogenic sources of heat like artificial heating and cooling of buildings, transportation and industrial processes cause distinct UHIs (Wilby, 2007; Landsberg, 1981; Oke, 1982). Different studies have explored the intensity of solar irradiance on building surfaces based on different urban characteristics (Dervishi and Mahdavi 2012, Orehounig et al.2014)

The constant increase in hard and heat absorbing surfaces, the density of our cities, and the reduction in natural vegetation are the main contributors to the heat island effect (Akbari et al., 2001; Douloset al., 2004; Rossi et al., 2014). Urban heat island increases the cooling energy consumption and the peak electricity demand during the summer period, raises the concentration of harmful pollutants like the tropospheric ozone and VOCs, increases the emissions of $\mathrm{CO} 2$ to the atmosphere, deteriorates indoor and outdoor thermal comfort during the warm periods, affects health conditions and increases mortality (Santamouris and Kolokotsa, 2016).

The impact of high ambient temperatures on health is documented in many recent studies. As reported, above a site-specific threshold ambient temperature, mortality rate increases rapidly (Bacciniet al. 2008), while the excess mortality above the threshold temperature in Europe, and may reach $15.2 \%$ (Hajat et al., 2006). In parallel, several studies have documented the serious deterioration of the outdoor comfort conditions because of the ambient temperature increase (Pantavou et al., 2011). Because of the higher urban temperatures, the emission and generation of urban pollutants and in particular of tropospheric ozone increases (Stathopoulou et al., 2008).

In recent years, several studies on UHI mitigation have attempted to map and classify a myriad of common mitigation strategies. Gartland (2008) distinguished between three major actions that could be implemented at the community level: cool roofing, cool paving, and cooling with trees and vegetation. Navigant Consulting (2009) listed four major mitigation technologies (cool roofs, cool pavements, green roofs and urban green areas, and vehicle paint), alongside some additional technologies of lesser prevalence (district cooling, water cooling, and using bamboo as construction material). Kleerekoper et al. (2012) described four main intervention domains: vegetation, water, built form, and material. Gago et al. (2013) identified two major types of UHI mitigation strategies: the first focuses on specific interventions in the cityscape, and includes parks and green areas, trees and vegetation, green roofs, albedo, and pavements; the other was defined as an "urban design" strategy preoccupied with the effect of design on solar radiation and airflow. Wong and Jusuf (2013) defined five major UHI mitigation strategies: urban climatic map at city level, urban climatic map at estate level, urban greenery, urban ventilation, and cool materials. Nuruzzaman (2015) suggested a list of eight mitigation strategies: high albedo roofing materials, high albedo pavements, green vegetation, shade trees, pervious pavements, water bodies, urban planning, and green roofs.

As a developing city, Tirana has had a rapid urbanization with a high population increase. The soft areas are replaced with hardscape, increasing the temperature, thermal discomfort and energy consumption in the city. Figure 1 shows the increase of mean temperatures during the last years. Tirana, like other Mediterranean cities, faces many thermal issues from high urban temperatures (Dervishi et. al. 2012). The aim of this paper is to analyse the actual conditions of urban heat island phenomena in Tirana and develop some strategies on how to mitigate the UHI effect to have a cooler city. 


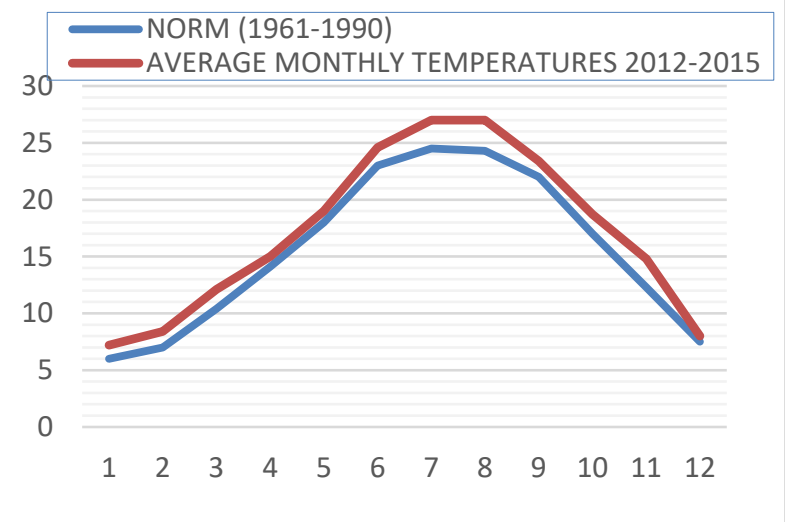

Figure 1: Mean monthly temperatures in 2002-2015 and for the reference period 1961-1990 in Tirana. (Source:IGEWE Tirana).

\section{Methodology}

\section{Site selection}

Three sites with different characteristics (built ratio, building heights, green spaces and materials) have been selected (see Figure 2). The first site (refereed as SF) is located near Artificial Lake of Tirana in "Sami Frasheri Street", with buildings that vary in height. The green surfaces and the lake near this site have a great impact on the air temperatures. The second site (refereed as AZC) is located adjacent to the first site, in Andon Zako Cajupi Street characterized by high raised buildings of high density. The third site (refereed as PM) is located in Prokop Myzeqari Street and is characterized by a combination of new high buildings and low raised houses with front courtyards.

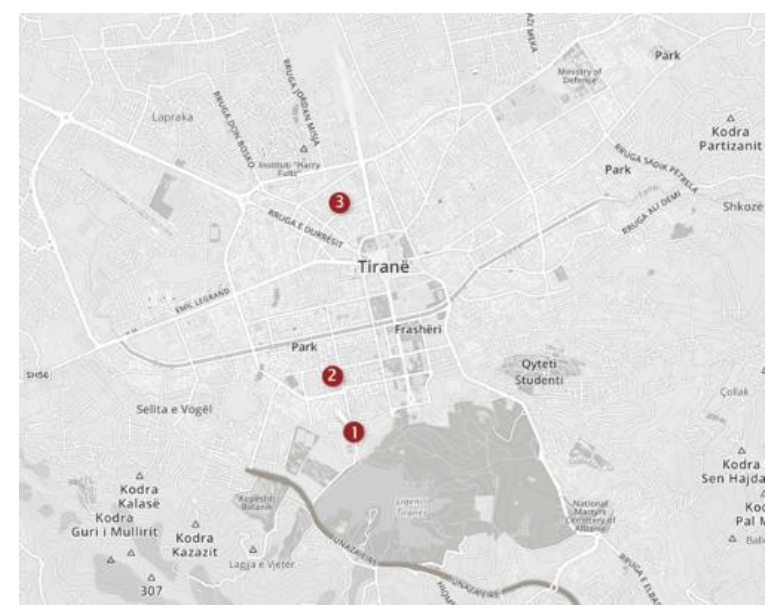

Figure 2: Location of three selected sites in Tirana, Albania

\section{Measurements}

The first step has been the collection and analysis of data for three months of summer 2017, taken from weather stations located on the sites. In order to compare the three sites in terms of the air temperature and humidity, August $9^{\text {th }}$ was selected as the reference day with the higher temperatures. The highest temperatures are registered at
Prokop Myzeqari (PM) zone, characterized also by the lowest humidity of three compared zones. The lowest values of high and low temperatures are registered at Sami Frasheri (SF) zone where the humidity has the highest value of three zones. The daily high temperatures of three zones during June, July and August 2017 is shown in Figure 3.

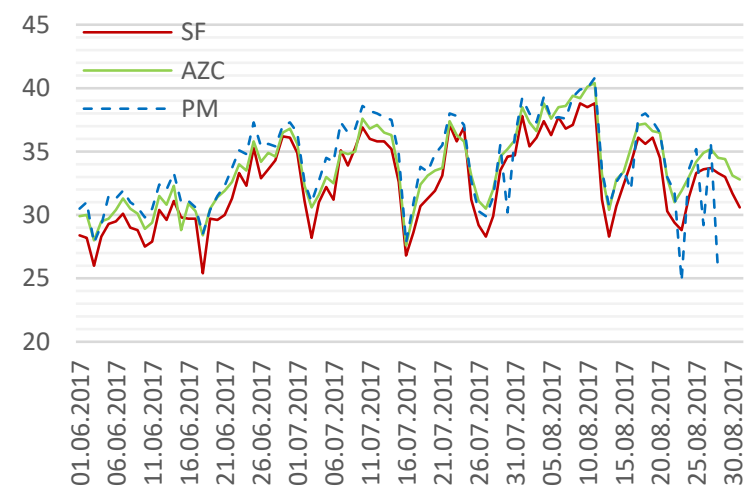

Figure 3: Daily High Temperature Graphic for June, July and August 2017.

In Table 1 below and in Figure 4,5 data for August $9^{\text {th }}$ has been given. SF and PM zones have a difference of 1.1 degree $\mathrm{C}$ between the values of high temperatures, 3.1 degree $\mathrm{C}$ between the values of low temperatures and 2.1 degree $\mathrm{C}$ between the values of average temperatures. In addition, SF zone has the highest humidity influenced by the presence of the lake and the park near the zone. If we compare the humidity percentage values in Figure 5, we notice that during the night hours and early morning these values are much higher in Sami Frasheri Zone.

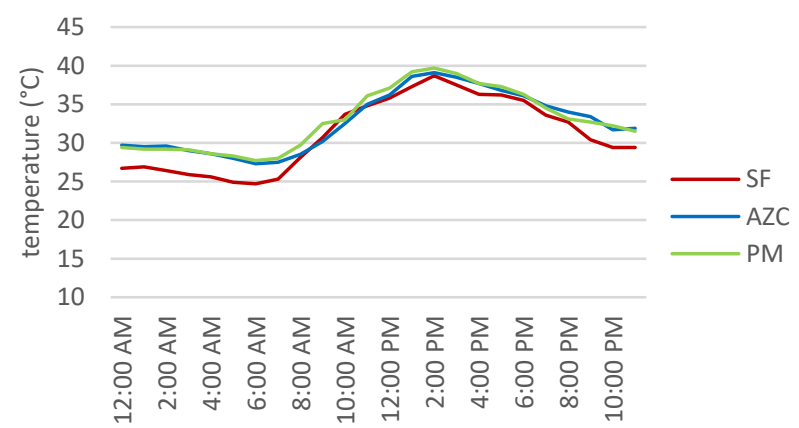

Figure 4: Temperature Values for August 9th. 


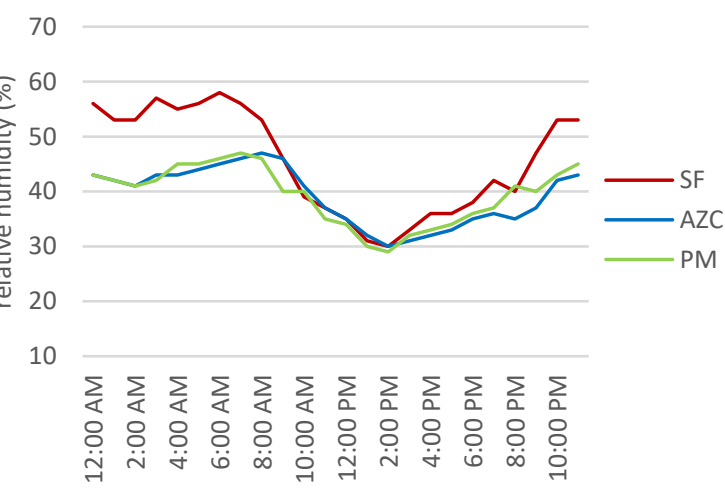

Figure 5: Humidity Values for August $9^{\text {th }}$.

Table 1: Weather information (temperature and relative humidity) for the selected sites for August $9^{\text {th }}$.

\begin{tabular}{|c|c|c|c|c|}
\hline \multicolumn{2}{|c|}{} & High & Low & Average \\
\hline \multirow{2}{*}{$\mathrm{SF}$} & Temperature & $38.8^{\circ} \mathrm{C}$ & $24.6^{\circ} \mathrm{C}$ & $31.7^{\circ} \mathrm{C}$ \\
\cline { 2 - 5 } & Humidity & $60 \%$ & $31 \%$ & $46 \%$ \\
\hline \multirow{2}{*}{$\mathrm{AZC}$} & Temperature & $39.2^{\circ} \mathrm{C}$ & $27.3^{\circ} \mathrm{C}$ & $33.2^{\circ} \mathrm{C}$ \\
\cline { 2 - 5 } & Humidity & $52 \%$ & $30 \%$ & $41 \%$ \\
\hline \multirow{2}{*}{$\mathrm{PM}$} & Temperature & $39.9^{\circ} \mathrm{C}$ & $27.7^{\circ} \mathrm{C}$ & $33.8^{\circ} \mathrm{C}$ \\
\cline { 2 - 5 } & Humidity & $47 \%$ & $29 \%$ & $39 \%$ \\
\hline
\end{tabular}

\section{Urban Context}

Based on orthophotos and site visits the plan was updated with the actual building footprints and heights, with the vegetation and roads. The selected site dimensions are three hundred meters by three hundred meters (300x300). Percentage of built area, street area and sky view factor have been calculated. It results that the most built area is PM zone and the less built area is SF zone. In Table 2, sky view factor, built area, street area, area, and coordinates of each zone are listed. Building typologies, greenery and pavement materials have been studied for each zone.

The used materials in the three zones are mostly masonry, brick, and concrete in buildings and asphalt and concrete bricks in streets and sidewalks. The roofs are mostly flat except PZ zone composed of shingled roofs of private villas.

Table 2: Data for the selected sites.

\begin{tabular}{|c|c|c|c|}
\hline Zones & SF & AZC & PM \\
\hline Coordinates & $41^{\circ} 18^{\prime} 55^{\prime \prime}$ & $41^{\circ} 19^{\prime} 10^{\prime \prime}$ & $41^{\circ} 19^{\prime} 57^{\prime \prime}$ \\
& $\mathrm{N}$ & $\mathrm{N}$ & $\mathrm{N}$ \\
& $19^{\circ} 48^{\prime} 55^{\prime}$ & $19^{\circ} 48^{\prime} 48^{\prime \prime}$ & $19^{\circ} 48^{\prime} 50^{\prime \prime}$ \\
$\mathrm{E}$ & $\mathrm{E}$ & $\mathrm{E}$ \\
\hline Area $\left(\mathrm{m}^{2}\right)$ & 90000 & 90000 & 90000 \\
\hline \% built area & $49 \%$ & $57 \%$ & $58 \%$ \\
\hline \% street area & $14 \%$ & $17.4 \%$ & $12.2 \%$ \\
\hline sky view & 0.34 & 0.28 & 0.35 \\
factor & & & \\
\hline
\end{tabular}

Sami Frasheri (SF) zone, located near Tirana Artificial Lake, is characterized by a combination of low, medium and high raised buildings up to eleven floors high. Most of the buildings are built after 90's but there are also buildings built during the communism period. The façade materials are mostly plaster. There is presence of vegetation along the streets, in public buildings' courtyards. The pavement material used in streets is dark asphalt and the pavement used in sidewalks is mostly grey concrete bricks (Figure 6). The left over space is usually filled with dark asphalt.
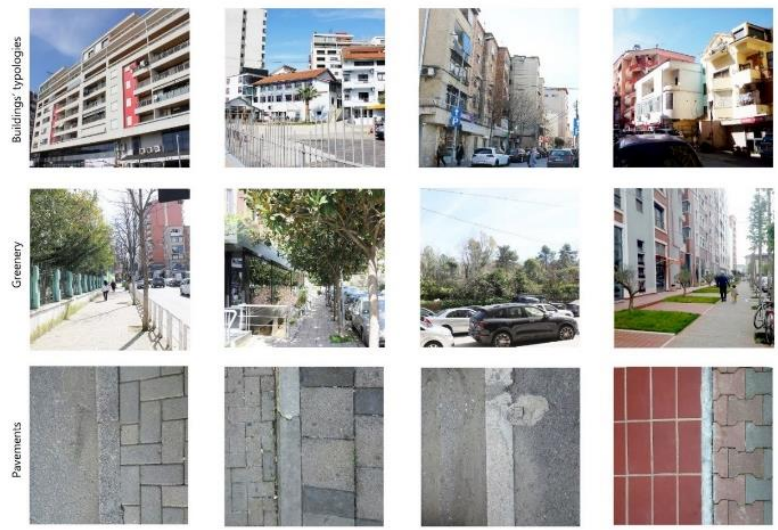

Figure 6: Site observation (Building's typology, greenery, pavements) of Sami Frasheri (SF) Street.

AZC zone is characterized by medium raised building built during the communism period and high raised buildings built after 1990 . The façade materials are mostly plaster and brick. There is presence of large high tress along main streets that during the summer provide a green shaded path. Greenery is also present in public spaces and institutions' courtyards. The pavement has problematic issues. The sidewalks are usually paved with dark asphalt, same as the roads (Figure 7). There are also sidewalks paved with concrete bricks. The main roads have a high traffic.
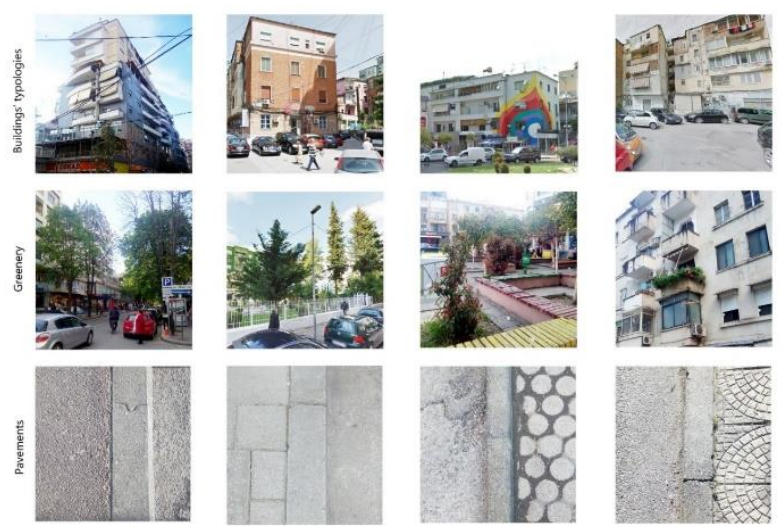

Figure 7: Site observation (Building's typology, greenery, pavements) of Andon Zako Cajupi (AZC) Street.

PM zone has a very organic development. It is a very dense built area. There is combination of building typologies starting from low raised shingled roof villas with medium raised building of communism period and 
high raised building built after 1990. Façade materials are colored plaster, silicate brick, and red brick. Greenery is mostly seen in private villas' courtyards and group of trees in different corners. The pavement material is mostly dark asphalt and concrete bricks (Figure 8).
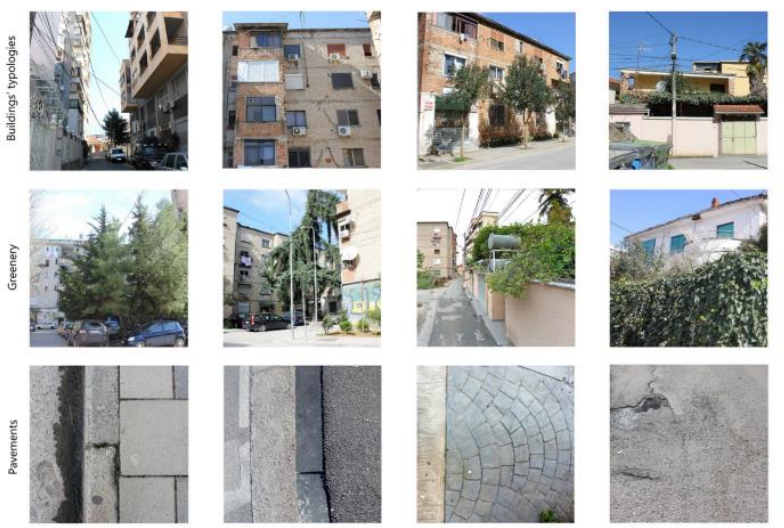

Figure 8: Site observation (Building's typology, greenery, pavements) of Prokop Myzeqari Street (PM)

Street.

\section{Simulations}

Envi-met computational simulation was chosen to analyze the effect of urban geometry, urban greenery, and materials in air temperature. The ENVI-met model consists of a one-dimensional boundary model, that includes vertical profiles of different meteorological parameters up until a height of 2500 meters and a threedimensional core model that includes all atmosphere, soil, building and vegetation processes. (Bruse, 2017)

The information gathered from the analysis and site observation (surface material, vegetation, soil type, building geometry and height) is incorporated into the simulation software (see figure 9 to 11). Based on the information of the weather stations located in the three site, input data is added into the Envi-Met Program including the initial wind speed $(\mathrm{m} / \mathrm{s})$, wind direction (deg), initial temperature $\left({ }^{\circ} \mathrm{C}\right.$ ) and Relative Humidity $(\%)$ (See Table 3). For the study, the main output parameters of ENVI-met, i.e. air temperature T, wind speed u, relative humidity $f_{\text {rel }}$ and mean radiant temperature $\mathrm{T}_{\mathrm{mrt}}$ are analysed.

Table 1: Input data to simulation file.

\begin{tabular}{|c|c|c|c|c|}
\cline { 2 - 5 } \multicolumn{1}{c|}{} & $\begin{array}{c}\text { Initial } \\
\text { wind } \\
\text { speed } \\
(\mathbf{m} / \mathbf{s})\end{array}$ & $\begin{array}{c}\text { Wind } \\
\text { Direction } \\
(\mathbf{d e g})\end{array}$ & $\begin{array}{c}\text { Initial } \\
\text { Temperature } \\
\left({ }^{\mathbf{}} \mathbf{C}\right)\end{array}$ & $\begin{array}{c}\text { Relative } \\
\text { Humidity } \\
(\boldsymbol{\%})\end{array}$ \\
\hline SF & 3.2 & 315 & 37.3 & 31 \\
\hline AZC & 3.2 & 315 & 38.6 & 32 \\
\hline PM & 3.2 & 270 & 39.2 & 30 \\
\hline
\end{tabular}

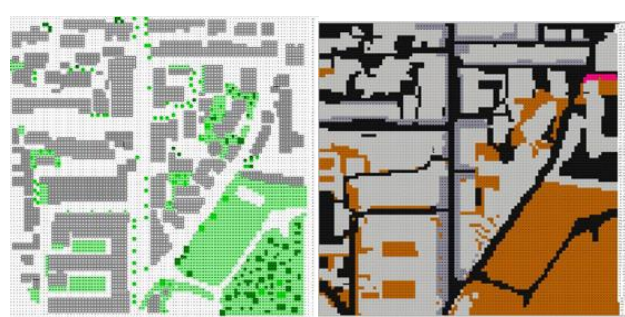

Figure 9: Buildings and Vegetation Model on the left; Soil and Surface Model on the right (SF).

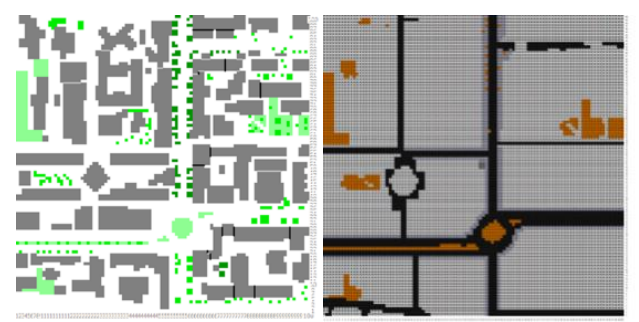

Figure 10: Buildings and Vegetation Model on the left; Soil and Surface Model on the right (AZC).

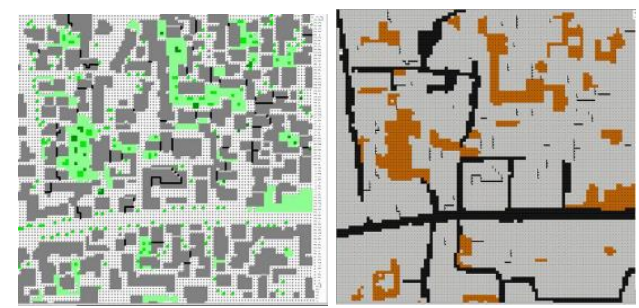

Figure 11: Buildings and Vegetation Model on the left; Soil and Surface Model on the right (PM).

\section{Results and Discussion}

\section{Simulation (base case scenario)}

"Sami Frasheri" Zone

As seen in Figure 12 the air temperature at 14:00, tend to be up to $3{ }^{\circ} \mathrm{C}$ lower in the area affected by greenery near the artificial lake. The air temperature has the lowest values in shaded areas with natural soils while the highest values can be observed over streets that are fully exposed to the sun. The air temperatures are higher around low raised buildings, opened spaces with no shade, lower around high raised buildings, and in areas covered by trees (see figure 13). 

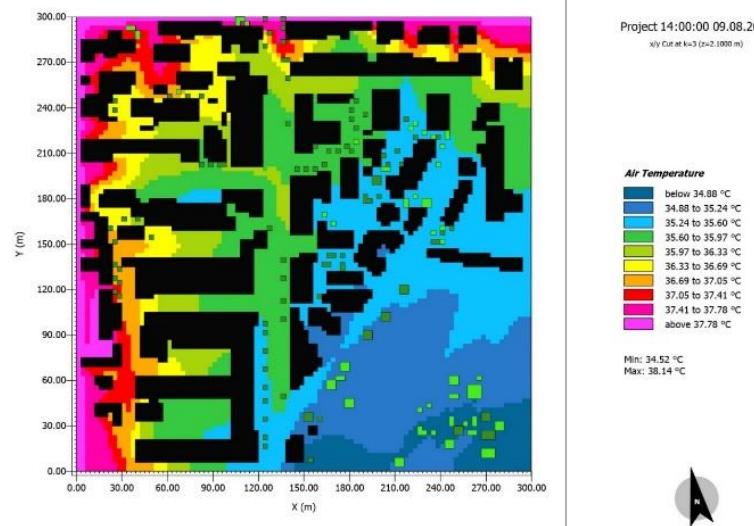

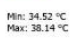

Figure 12: Air Temperatures at 14:00 (SF).
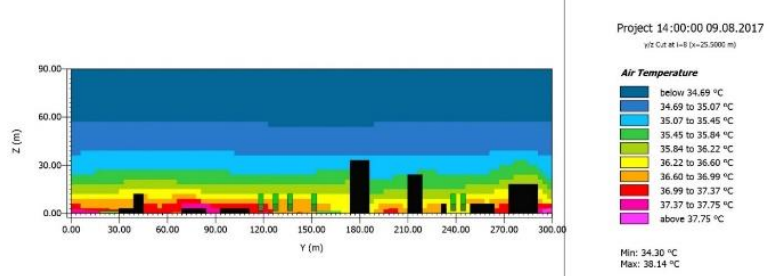

Figure 13: Air Temperature Section SF $x=25.5 \mathrm{~m}$.

Mean Radiant Temperature values show a strong correlation to the surface type. As figure 14 illustrates, the surface temperature in shaded area by the buildings goes up to $26{ }^{\circ} \mathrm{C}$ (14:00 o'clock) lower than in the areas with no shade and no vegetation. The temperature in areas covered by high crown trees is reduced from $7{ }^{\circ} \mathrm{C}$ to 22 ${ }^{\circ} \mathrm{C}$ lower. At 14:00 o'clock, the land cover material does not seem to have a considerable impact on surface temperature in sun-exposed areas. The surface temperature at this hour are mostly influenced by the shadow. In addition, the wind speed is lower at ground level and in denser built areas. While it becomes higher in large open spaces. The open corridor streets show a higher wind speed.
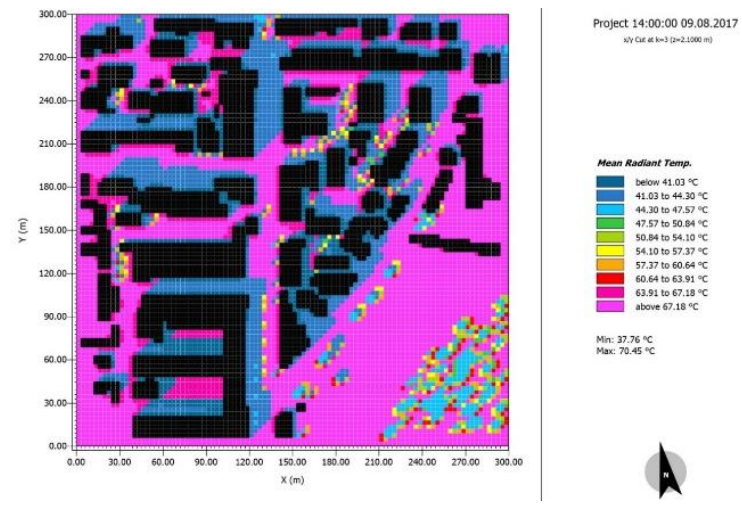

Figure 14. Mean Radiant Temperature at 14:00 SF.

\section{"Andon Zako Cajupi" Zone}

The simulations show that air temperature at 14:00 is in indirect relation with relative humidity and wind speed and in direct relation with mean radiant temperature. The air temperature is lower in areas with higher humidity and higher wind speed. The temperature seems to be lower along the main street, which acts as a cooling corridor affected by wind speed and presence of high trees. In addition, the high raised building affect the surrounding air temperature making it lower by providing shadow. The highest values can be observed over the other main street and in areas that are fully exposed to the sun (see figure 15). From the sections of air temperature illustrated. The air temperatures are higher around low raised buildings, opened spaces with no shade, lower around high raised buildings, and in areas covered by trees (see figure 16).

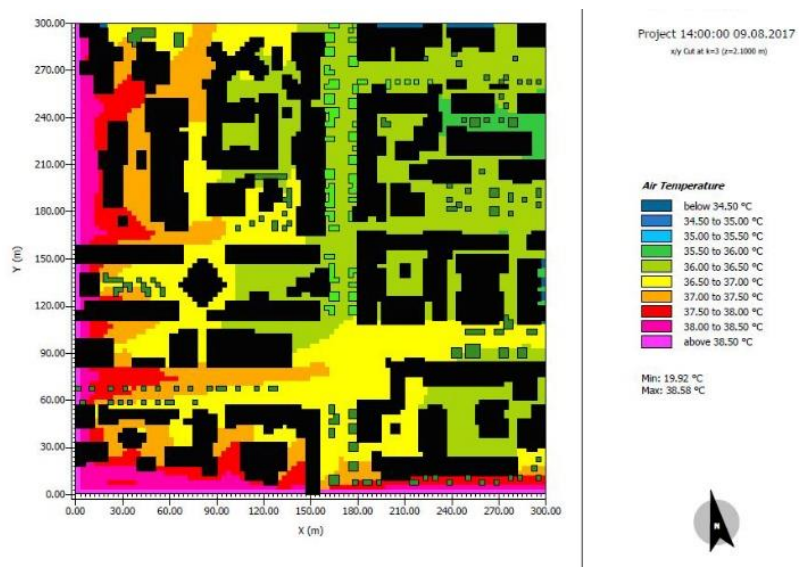

Figure 15: Air Temperature 14:00 AZC.

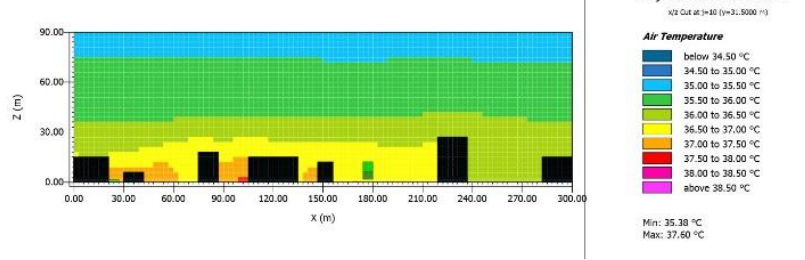

Figure 16: Air Temperature Section AZC y=31.5m.

Mean Radiant Temperature values are strongly related to the land cover. In AZC zone we don't have large green area as in SF zone but the difference in surface temperature is mostly seen in shaded and non-shaded areas by the buildings but also by high trees (Figure 17). The shading provided by high raised buildings affects the air temperature and Tmrt providing cooler surface temperature. The surface temperature at 14:00 o'clock in shaded areas by the buildings goes up to $26^{\circ} \mathrm{C}$ lower than in the areas with no shade and no vegetation. The temperature in areas covered by high crown trees varies from $6{ }^{\circ} \mathrm{C}$ to $26{ }^{\circ} \mathrm{C}$ lower (see figure 17). $\mathrm{T}_{\text {mrt }}$ during 18:00 o'clock varies from $25.61{ }^{\circ} \mathrm{C}$ up to $34.97{ }^{\circ} \mathrm{C}$. The land cover material does not seem to have a considerable impact on surface temperature in sun-exposed areas. Shadow is the element, which influences the surface temperature at this hour. At 18:00 o'clock, the temperature difference between different materials becomes more evident because of the heat accumulated during the day. Except shadows, we can see the difference in surface temperature between asphalt and light concrete 
pavement used in sidewalks. Light concrete it is a more reflective material than dark asphalt thus it accumulates less heat during the day.
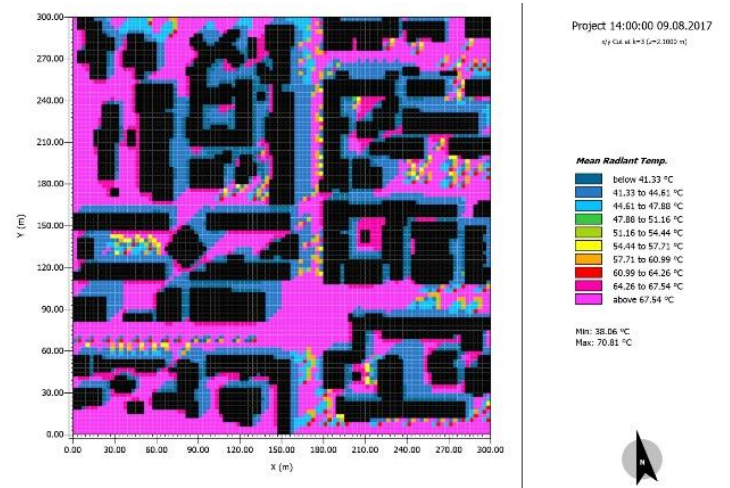

Figure 17: Mean Radiant Temperature 14:00 AZC.

Relative humidity during 14:00 o'clock is shown in Figure 18. The indirect relation between air temperature and humidity can be understood.
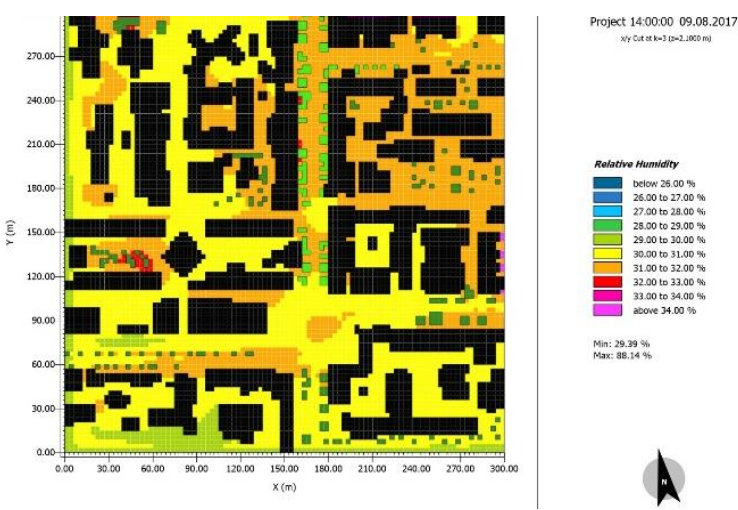

Figure 18: Relative Humidity AZC 14:00

"Prokop Myzeqari” Zone

Prokop Myzeqari Zone is the most built up area with high density and variety in building heights. The simulation of air temperature at 14:00 show that the temperatures are lower around high raised buildings and in areas with trees (Figure 19). From the section illustrated in Figure 20 we understand that the air temperatures are higher around low raised buildings and opened spaces with no shade and lower around high raised buildings and in areas covered by trees. Buildings with narrow distance between them create cool paths.

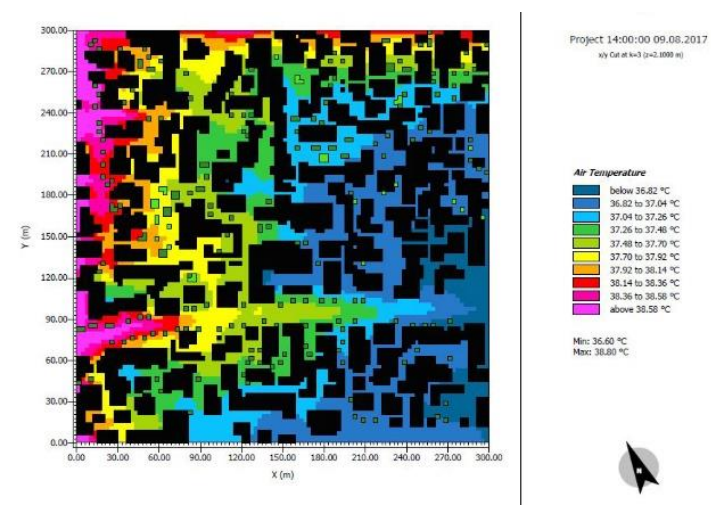

Figure 19: Air Temperature PM 14:00.

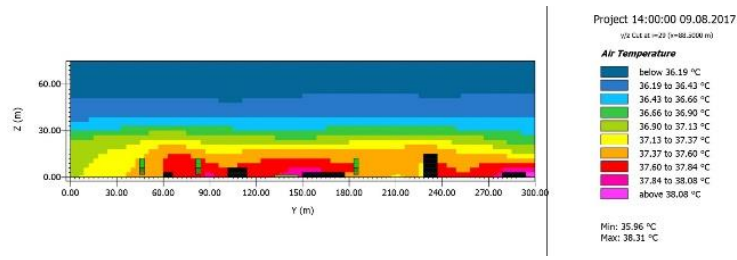

Figure 20: Air Temperature Section AZC y=31.5m.

Mean Radiant Temperature values are strongly related to the landcover. The difference in surface temperature is mostly seen in shaded and non-shaded areas by the buildings but also by high trees (Figure 21). The shading provided by high raised buildings affects the air temperature and $\mathrm{T}_{\mathrm{mrt}}$ providing cooler surface temperature. The surface temperature in shaded areas by the buildings goes up to $28^{\circ} \mathrm{C}$ lower than in the areas with no shade and no vegetation. The temperature in areas covered by high crown trees varies from $8{ }^{\circ} \mathrm{C}$ to $24{ }^{\circ} \mathrm{C}$ lower. $\mathrm{T}_{\text {mrt }}$ during 18:00 o'clock varies from $26.35{ }^{\circ} \mathrm{C}$ up to $35.34^{\circ} \mathrm{C}$. The land cover material does not seem to have a considerable impact on surface temperature in sunexposed areas. Relative humidity during 14:00 o'clock is shown in Figure 22. The main street with green and blue colour has low values of humidity and high values of air temperature. The wind speed seems to be higher along the main open street and lower up to $0 \mathrm{~m} / \mathrm{s}$ in dense built areas (Figure 23).
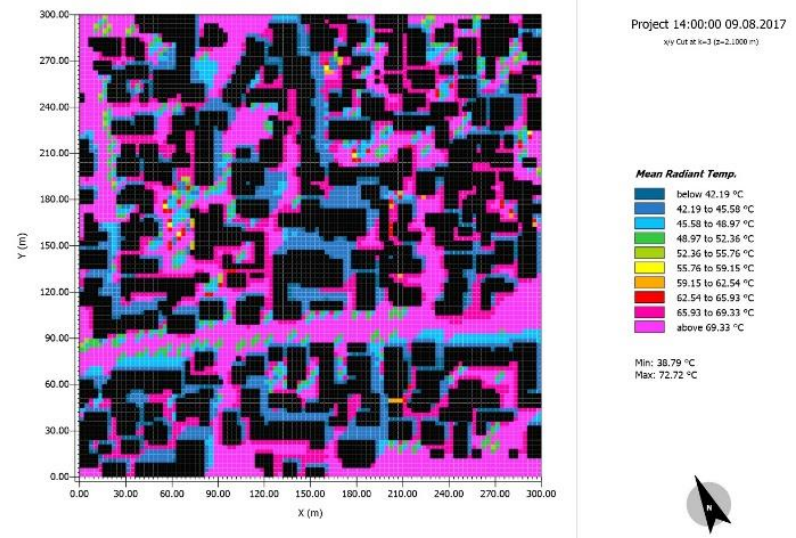

Figure 21: Mean Radiant Temperature PM 14:00. 


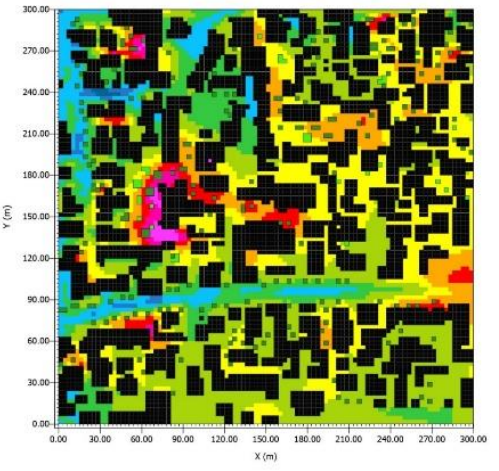

Project 14:00:00 09.08.2017

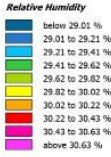

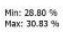

Figure 22: Relative Humidity PM 14:00.
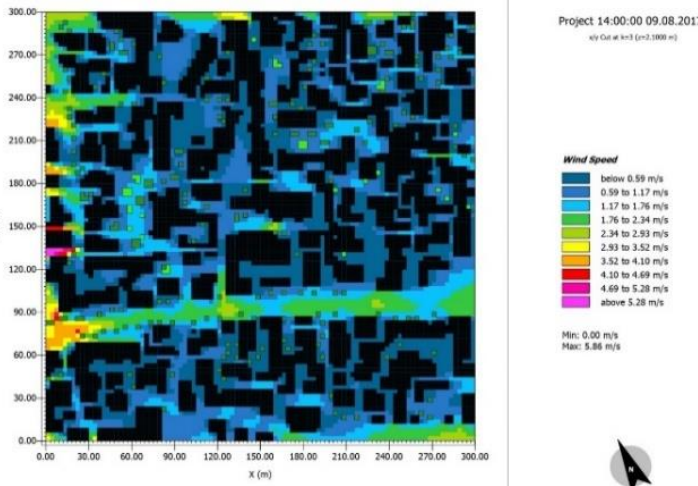

Figure 23: Wind Speed PM 14:00.

\section{Optimization "Andon Zako Cajupi Zone"}

AZC Zone was chosen to make an optimization consisting in different pavement materials and increasing urban greenery. For the roads instead of asphalt photocatalytic concrete was used. For the other pavements was used light concrete pavement (Figure 24). Greenery was added along the streets but also in open areas (Figure 25).
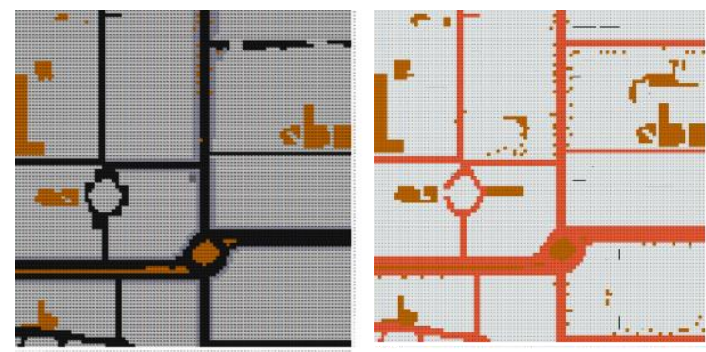

Figure 24: Land Cover before and after.
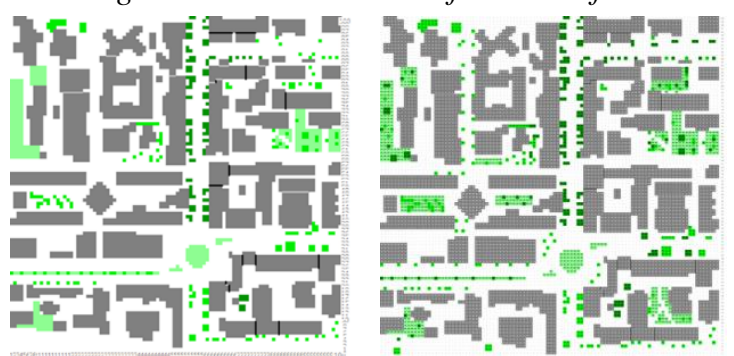

Figure 25: Greenery before and after.
The results of the simulations after the optimization show significant changes in air temperature and mean radiant temperature. A figure 26 illustrates, we see that after the optimization the green color $35.5^{\circ} \mathrm{C}-36.5^{\circ} \mathrm{C}$ has a higher distribution along the site. The Mean Radiant Temperature difference during 14:00 is mostly seen in areas where greenery is added (Figure 27). In Figure 28 at 18:00 we can see the significant change of Tmrt after optimization. If we compare the results the surface temperatures of the paved area reach up to $10{ }^{\circ} \mathrm{C}$ difference before and after the optimization and shade provided by proposed greenery offers surface temperatures up to $25^{\circ} \mathrm{C}$ lower than the paved surface.
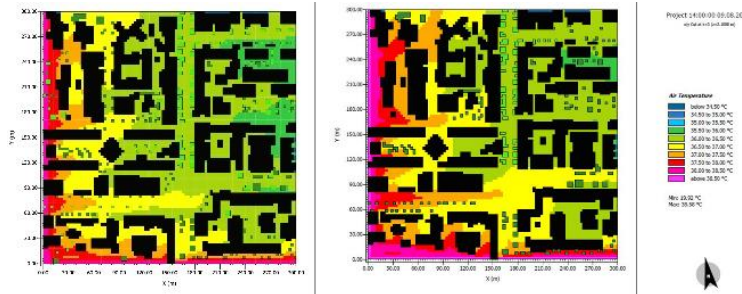

Figure 26: Air temperature 14:00 before and after.
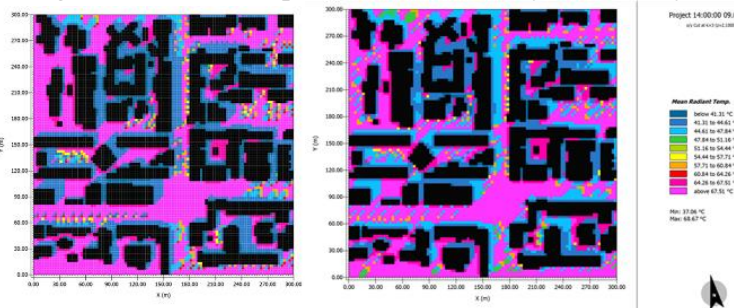

Figure 27: Mean Radiant Temperature 14:00 before and after optimization.
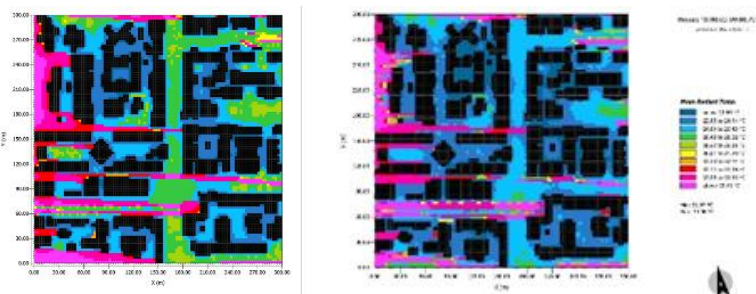

Figure 28: Mean Radiant Temperature 18:00 before and after optimization.

\section{Conclusion}

In this study, three sites with different characteristics were analysed focused in air temperature, mean radiant temperature, humidity and wind speed. The simulations show different results of three areas due to urban pattern, building morphology and landcover. The lowest temperatures are registered at Sami Frasheri Zone and the highest temperatures are registered at Prokop Myzeqari Zone. The air temperature has the lowest values in shaded areas with natural soils while the highest values can be observed over streets that are fully exposed to the sun. All simulations show the same results: an unaltered airflow and a high density of vegetation with a distinct and dense crown layer can significantly improve the summer air temperature and human thermal comfort. The shading 
provided by high raised buildings affects the air temperature and Mean Radiant Temperature providing cooler surface temperature. Generally mean radiant temperature simulation during 14:00 in three zones show that the surface temperature in shaded area by the buildings goes up to $26^{\circ} \mathrm{C}$ lower than in the areas with no shade and no vegetation. The temperature in areas covered by high crown trees varies from $7{ }^{\circ} \mathrm{C}$ to $22{ }^{\circ} \mathrm{C}$ lower. Optimization of AZC zone made based on two mitigation strategies resulted in more than $1{ }^{\circ} \mathrm{C}$ lower air temperature and $25^{\circ} \mathrm{C}$ lower mean radiant temperature.

Future scope of this project could be the analysis of UHI effects on buildings energy performance thus going into a smaller scale.

\section{References}

Akbari, H., Cartalis, C., Kolokotsa, D., Muscio, A., Pisello, A.L., Rossi, F., Santamouris, M., Synnefa, A., Wong, N., \& Zinzi, M. (2016). Local climate change and urban heat island mitigation techniques - the state of the art, Journal of Civil Engineering and Management, 22:1, 1-16,

Bruse, M., H. Fleer (1998), Simulating surface-plant-air interactions inside urban environments with a three dimensional numerical model, Environmental Modelling \& Software, 13:3-4, 373-384.

Bruse, M. (2017), ENVI-met website. Retrieved from http://www.model.envi-met.com/hg2e/doku.php

Dervishi, S., Lacaj, E., and Vathi, R. (2012). Urban heat islands (UHI) mitigation in densely urban city of Tirana, Albania: Materials, energy, comfort," International Journal of Business and Technology: Vol. 1 : Iss. 1 , Article 6.

Dervishi S., Mahdavi A. 2012. Computing diffuse fraction of global horizontal solar radiation: A model comparison. Solar Energy 86 (6):1796-1802

European Environment Agency (EEA). (2015). SOER 2015 - the European environment - state and outlook. A comprehensive assessment of the European environment's state, trends and prospects, in a global context. SOER 2015 Report. 212 p.

European Environment Agency (EEA). (2012). Climate change, impacts and vulnerability in Europe. An indicator-based report. Report No. 12/2012. 300 p.
Gartland, L., (2008). Heat Islands: Understanding and Mitigating Heat in Urban Areas. Earthscan, London; Sterling, VA.

Giguère, M., (2009). Literature Review of Urban Heat Island Mitigation Strategies. Institut national de santé publique Québec, Québec

Landsberg, E.H., 1981, The Urban Climate, Maryland, Academic Press.

Landsberg, H.E., 1982. The Urban Climate.. International Geophysics Series, Vol. 28. Academic Press,New York.

Nuruzzaman, M., (2015). Urban heat island: causes, effects and mitigation measures - a review. International Journal of Environmental Monitoring and Analysis 3 (2), 67

Oke, T.R., (1982). The energetic basis of the urban heat island (Symons Memorial Lecture, 20 May 1980). Quarterly Journal, Royal Meteorological Society 108, $1-24$.

Oke, T.R., Johnson, G.T., Steyn, D.G., Watson, I.D., (1991). Simulation of surface urban heat islands under ideal conditions at night. 2. Diagnosis of causation boundary layer. Meteorology 56 (4), 339-358.

Orehounig K., Dervishi, S., Mahdavi, A. 2014. Computational derivation of irradiance on building surfaces: An empirically-based model comparison. , Renewable Energy 71:185-192

Santamouris, M., (2013). Using cool pavements as a strategy to fight urban heat island - a review of the actual developments. Renew. Sust. Energ. Rev. 26, 224-240.

Santamouris, M., Kolokotsa, D., (2016). Urban Climate Mitigation Techniques. Taylor \& Francis Group Ltd, 2 Park Square, Milton Park, Abingdon, Oxford, OX14 4RN, UK.

Stathopoulou, E., Mihalakakou, G., Santamouris, M., Bagiorgas, H.S., (2008). Impact of temperature on tropospheric ozone concentration levels in urban environments. J. Earth Syst. Sci. 117 (3), 227-236.

Wilby, R. L. (2007). A review of climate change impacts on the built environment, Built Environment 33(14): $31-45$.

Zulia, E., Santamouris, M., Dimoudi, A., (2009). Monitoring the effect of urban green areas on the heat island in Athens. Environ. Monit. Assess. 156 (1-4), 275-2 